\title{
ENDOTHELIAL DYSFUNCTION AND CARDIOVASCULAR RISK IN PATIENTS WITH ANKYLOSING SPONDYLITIS
}

\author{
S. I. Smiyan, B. O. Koshak, I. V. Gnatko \\ I. HORBACHEVSKY TERNOPIL STATE MEDICAL UNIVERSITY, TERNOPIL, UKRAINE
}

Background. Ankylosing spondylitis is a disease that induces damage to the musculoskeletal system. Mortality rate among patients with AS is in 1.5 times higher than the population level. It is caused by cardiovascular disease and chronic renal failure.

Objective. The research was aimed to study the prevalence of endothelial dysfunction and to establish its dependence on the factors of cardiovascular risk in patients with AS.

Methods. 104 patients with ankylosing spondylitis (AS) were examined using standard diagnostic methods, such as disease activity, lipidogram, ultrasound of the carotid artery intima media, and endothelium vasodilatation in response to reactive hyperaemia was evaluated. Clinical activity of the disease was determined using the disease activity index BASDAI, BASFI functional index, index BASMI metrology, ASQoL quality of life. To estimate the 10year risk of cardiovascular disease, the QRISK scale was used.

Results. Endothelial dysfunction (ED) was found in 47\% cases. It was established that in the patients with $E D<10 \%$ the incidence of $L P L>1.7 \mathrm{mg} / \mathrm{L}, \mathrm{HDL}-C<1.0 \mathrm{mmol} / \mathrm{L}$, TIM thickening $>0.9 \mathrm{~mm}$ was higher than in the patients with ED>10\%. In this group of patients, significant duration of the disease and essential differences in their progress in terms of VAS, CRP, ESR, index activity and functional disorders were revealed.

Conclusions. The problem of CVD in patients with AS may be caused by systemic inflammatory disease associated with the development of endothelial dysfunction and increased levels of atherogenic lipids.

KEY WORDS: ankylosing spondylitis; endothelial dysfunction; cardiovascular risk.

\section{Introduction}

Ankylosing spondylitis (AS) is a chronic systemic inflammatory disease primarily involving the axial skeleton (sacroiliac, intervertebral joints) $[1 ; 12]$ and belongs to the group of seronegative spondylitis (SnA).

Mortality among patients with AS is in 1.5 times higher than the population levels. [8] It is caused by cardiovascular disease and chronic renal failure [3]. It is established that the presence of chronic systemic inflammation is an important predictor of cardiovascular (CV) disease $[5 ; 7 ; 12]$ due to the development of endothelial dysfunction, and further - atherosclerosis and atherothrombosis, remodelling of vascular wall and myocardium [10] and, therefore, the main cause of numerous life-threatening adverse conditions.

Specifics of endothelial dysfunction development have been well studied in patients with rheumatoid arthritis, systemic lupus erythe-

Corresponding author: Bohdan Koshak, Department of Internal Medicine № 2, I. Horbachevsky Ternopil State Medical University, 1 Clinichna Street, Ternopil, Ukraine, 460002 Phone number: +380987123099

E-mail: Koshak_bohdan@yahoo.com matosus. At the same time, despite widespread prevalence of AS, this aspect has not been discussed and analyzed in a cohort of these patients so far. There is scanty information of the impact of systemic inflammation activity on the functional state of endothelium in cases of AS, and of the possibility of endothelial dysfunction correction against the background of anti-inflammatory therapy. The research was aimed to study the prevalence of endothelial dysfunction and to establish its dependence on the factors of cardiovascular risk in patients with AS.

\section{Methods}

104 patients (90 males and 14 females) with verified diagnosis of AS were examined. They were hospitalized into the Department of Rheumatology of Ternopil University Hospital within 2015-2017. The study inclusion criteria were: the diagnosis of AS according to the modified New York criteria and the informative patient's consent to participate in the study. Exclusion criteria were age over 60 years old, presence of psoriasis, Crohn's disease, ulcerative colitis, coronary heart disease, manifes- 
tations of peripheral atherosclerosis, clinically significant heart disease, circulatory insufficiency of any origin, diabetes, severe liver disease, kidney diseases and other chronic diseases in their acute phases. All patients who agreed to participate in the study underwent general clinical examination (common blood test, urinalysis, ECG, X-ray of sacroiliac joints), biochemical test of blood with determination of lipidograma and acute phase indicators (C-reactive protein, rheumatoid factor and etc.) and detection of HLA B-27. Clinical activity of the disease was determined using the disease activity index BASDAI, BASFI functional index and BASMI metrology index, ASQoL quality of life $[2,4]$. Endothelium vasodilatation was evaluated in response to reactive hyperaemia in 57 patients by the method, which was first described by D. Celermajer [9], using Acuson $128 \mathrm{XP} / 10$ ultrasonic complex equipped with a $7 \mathrm{MHz}$ linear transducer. The study was conducted in a duplex mode (ultrasound scanning in B-mode and Doppler spectral analysis of the signal). Tests with reactive hyperaemia (endothelium-dependent vasodilators) and nitro-glycerine (endothelium-independent vasodilators) were performed [10].

Endothelium-dependent vasodilatation (EDVD) was calculated by the formula: $E D V D=(d 60-d 0) \times 100 \% / d 0$, where $d 60$ is the brachial artery diameter 60 seconds after the restoration of blood flow, d0 - the initial diameter of brachial artery. Endothelium-independent vasodilatation (EIVD) was calculated by the formula: EIVD $=(d 5-d 0) \times 100 \% / d 0$, where $d 5$ the diameter of brachial artery after 5 minutes of taking nitro-glycerine, do - the initial diameter of brachial artery.

To determine the correlation between EIVD and EDVD, the reactivity index (IR) of brachial artery was calculated using the formula: IR=EIVD/EDVD. To assess the 10-year risk of cardiovascular disease, the scale QRISK was used (Q-RESEARCH Cardiovascular Risk Algorithm). The advantage of this scale is the use of such risk factors: age, sex, smoking, systolic blood pressure, the ratio of total cholesterol and HDL cholesterol, body mass index, family history of coronary artery disease, socioeconomic status, treatment with antihypertensive drugs and the presence of comorbidity, systemic inflammatory disease in an individual case.

Statistical analysis of the results was carried out using traditional methods of ANOVA, SPSS 22 (৫ SPSS Inc.).

\section{Results}

The main part of patients was of working age (mean age $-35.9 \pm 17.1$ years old, duration of the disease averaged $15.9 \pm 8.2$ years (Fig. 1)). Peripheral form of the disease was found in 35 patients $(33.7 \%)$, central form - in 69 patients (66.3\%). Evaluation of the disease proved the presence of high and moderate activity in the absence of disease in patients who had inactive or active course.

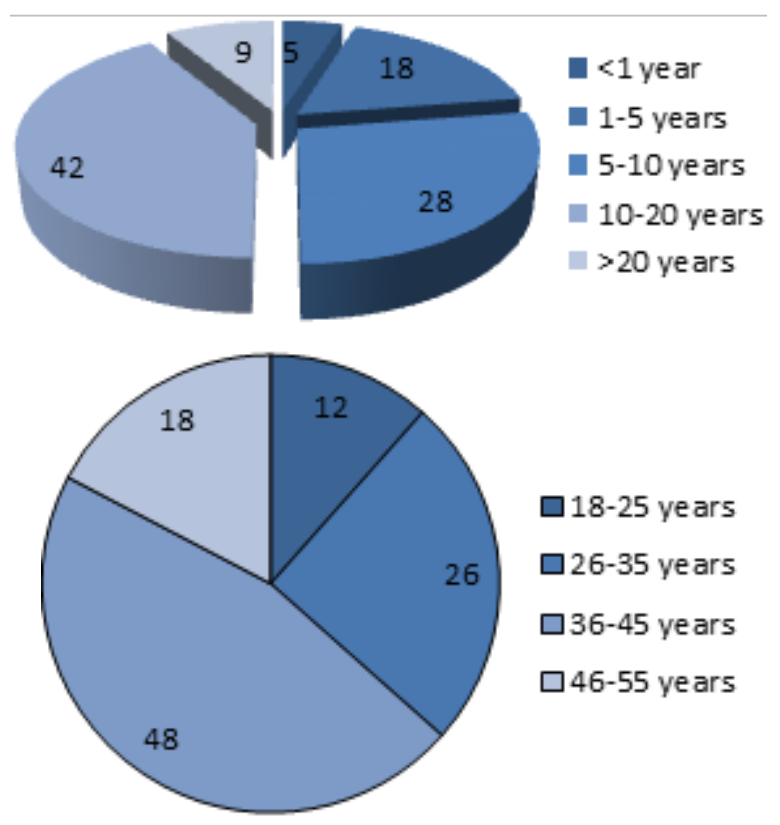

Fig. 1. Classification of patients according to age and disease duration

The research of endothelium functions in the patients with AS and in the control group proved that remodulation of vessels occurred due to endothelium dilation of brachial artery in response to reactive hyperaemia and that they differ slightly in the quantitative value of the indicator in the control group. Besides, EDVD reduced (less than 10\%), that is a sign of endothelial dysfunction, more common among patients with AS as compared to the control group ( $45.7 \%$ vs. $11.8 \%$, respectively). EIVD is significantly higher than EDVD in patients with AS and healthy individuals. However, EIVD in the patients with AS was found to exceed significantly the EDVD in the control group (Table 1).

In what follows, we evaluated clinical and laboratory characteristics of AS in patients with reduced EIVD (Table 2 ). The data proved that in the patients with impaired endothelial vasoregulation function, a significantly longer duration of disease was revealed, the onset of the illness symptoms was evidenced in younger 
Table 1. Results of endothelia vasoregulation function

\begin{tabular}{|l|c|c|c|}
\hline \multicolumn{1}{|c|}{ Indices } & AS $(\mathrm{n}=57)$ & $\begin{array}{c}\text { The control } \\
\text { group }(\mathrm{n}=20)\end{array}$ & $\mathrm{p}$ \\
\hline The initial diameter of brachial artery, $\mathrm{mm}$ & $4.32 \pm 0.29$ & $3.78 \pm 0.18$ & $\mathrm{p}<0.05$ \\
\hline The wall thickness of brachial artery, $\mathrm{mm}$ & $0.58 \pm 0.06$ & $0.41 \pm 0.03$ & $\mathrm{p}<0.05$ \\
\hline The output speed of blood flow, $\mathrm{m} / \mathrm{s}$ & $0.72 \pm 0.09$ & $0.68 \pm 0.07$ & $\mathrm{p}<0.05$ \\
\hline EDVD, \% & $9.8 \pm 1.23$ & $13.3 \pm 1.1$ & $\mathrm{p}<0.05$ \\
\hline EIVD, \% & $25.4 \pm 2.14$ & $19.7 \pm 5.4$ & $\mathrm{p}<0.05$ \\
\hline Brachial artery reactivity index & $2.35 \pm 0.12$ & $1.37 \pm 0.14$ & $\mathrm{p}<0.05$ \\
\hline
\end{tabular}

Note: $p$ - significant differences between the baselines indicators of the study and control groups.

Table 2. Clinical and laboratory characteristics of patients with AS

\begin{tabular}{|c|c|c|c|c|c|}
\hline Indices & \multicolumn{2}{|c|}{$\begin{array}{c}\text { EDVD }>10 \% \\
(n=31)\end{array}$} & \multicolumn{2}{|c|}{$\begin{array}{c}\text { EDVD }<10 \% \\
(n=26)\end{array}$} & $\mathrm{p}$ \\
\hline Disease duration, (yrs) & \multicolumn{2}{|c|}{$13.7 \pm 5.2$} & \multicolumn{2}{|c|}{$16.1 \pm 4.8$} & $p>0.05$ \\
\hline Age of disease onset, (yrs) & \multicolumn{2}{|c|}{$25.8 \pm 3.2$} & \multicolumn{2}{|c|}{$23.2 \pm 2.1$} & $p>0.05$ \\
\hline \multirow[t]{2}{*}{ The presence of peripheral arthritis } & $\mathrm{n}$ & $\%$ & $\mathrm{n}$ & $\%$ & \multirow[t]{2}{*}{$p>0.05$} \\
\hline & 10 & 32.3 & 9 & 34.6 & \\
\hline BASDAI, sm & \multicolumn{2}{|c|}{$4.64 \pm 0.42$} & \multicolumn{2}{|c|}{$6.80 \pm 0.27$} & $\mathrm{p}<0.05$ \\
\hline BASFI, sm & \multicolumn{2}{|c|}{$4.34 \pm 0.28$} & \multicolumn{2}{|c|}{$5.74 \pm 0.18$} & $\mathrm{p}<0.05$ \\
\hline DFI, points & \multicolumn{2}{|c|}{$15.8 \pm 1.1$} & \multicolumn{2}{|c|}{$17.1 \pm 0.89$} & $\mathrm{p}<0.05$ \\
\hline VAS, $\mathrm{mm}$ & \multicolumn{2}{|c|}{$61.9 \pm 14.5$} & \multicolumn{2}{|c|}{$80.3 \pm 12.4$} & $\mathrm{p}<0.05$ \\
\hline C-reactive, mg/l & \multicolumn{2}{|c|}{$8.3 \pm 1.4$} & \multicolumn{2}{|c|}{$15.2 \pm 2.7$} & $\mathrm{p}<0.05$ \\
\hline $\mathrm{ESR}, \mathrm{mm} / \mathrm{h}$ & \multicolumn{2}{|c|}{$18.3 \pm 3.2$} & \multicolumn{2}{|c|}{$28.5 \pm 4.1$} & $\mathrm{p}<0.05$ \\
\hline
\end{tabular}

Note: $p$ - significant differences between $E D<10 \%$ and $E D>10 \%$.

age. In addition, the patients with impaired EDVD had significantly higher indices of VAS and activity (BASDAI) with significantly higher than quantitative indicators of CRP, ESR, functional disorders and DFI.

Among the patients with EIVD $<10 \%$ (26 patients), 14 (53.8\%) are treated with NSAIDs, only $4(28.5 \%)$ of them - continuously. Among the patients with EDVD>10\% (31 patients), 28 persons underwent NSAIDS therapy, 19 of them - continuously (Fig. 2)

Classical cardiovascular risk factors and arterial hypertension are crucial for the development of endothelial dysfunction, so their prevalence in the group of the examined patients was analysed (Table 3).

About every third patient suffered from II degree hypertension, and the frequency of its registration was found to be similar to the prevalence among the general population (in the city area $-29.3 \%$, in rural - the prevalence of hypertension - 36.3\%) [13].

It should be noted that adequate antihypertensive therapy at the time of inclusion into the study was provided for 14 patients (39\%). Thickening of intima-media common carotid artery $>1 \mathrm{~mm}$ was found in $19.2 \%$ patients with
AS. High incidence of smoking among patients with AS can be due to the predominance of males. Many patients had reduced levels of HDL and high LDL levels that can be attributed to scanty availability of patients with hypercholesterolemia.

Mean BMI in the studied patients was $20.2 \pm 4.9 \mathrm{~kg} / \mathrm{m}^{2} ; 72(69.2 \%)$ patients had normal weight (BMI 18.5-24.9 kg/m²), $18(17.3 \%)$ patients had a deficit of body weight $\left(B M I<18.5 \mathrm{~kg} / \mathrm{m}^{2}\right)$,

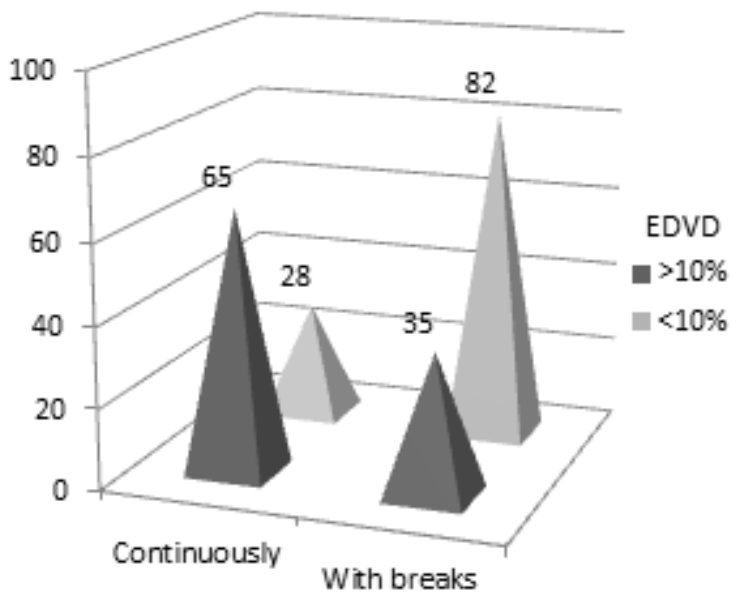

Fig. 2. Dependence of EDVD on the duration of NSAID treatment 
Table 3. The prevalence of traditional cardiovascular risk factors

\begin{tabular}{|l|c|c|}
\hline \multicolumn{1}{|c|}{ Sign } & $\mathrm{n}$ & $\%$ \\
\hline Arterial hypertension & 23 & 22.1 \\
\hline TIM of common carotid artery $>1 \mathrm{~mm}$ & 49 & 47.1 \\
\hline Smoking & 34 & 32.7 \\
\hline Hypercholesterolemia $(\mathrm{TCh}>5.2 \mathrm{mmol} / \mathrm{l})$ & 22 & 21.2 \\
\hline Low level of $\mathrm{HDL}(<1 \mathrm{mmol} / \mathrm{l}$ for male and $<1.2 \mathrm{mmol} / \mathrm{l}$ for female) & 63 & 60.6 \\
\hline High level of $\mathrm{LDL}(>3.0 \mathrm{mmol} / \mathrm{I})$ & 41 & 39.4 \\
\hline Hypertriglyceridemia $(\mathrm{Tr}>1.7 \mathrm{mmol} / \mathrm{I})$ & 14 & 13.5 \\
\hline Overweight $\left(\mathrm{BMI}>25 \mathrm{~kg} / \mathrm{m}^{2}\right)$ & 12 & 11.5 \\
\hline Family history of early heart disease & 16 & 15.4 \\
\hline
\end{tabular}

and $10(9.6 \%)$ patients had excessive body weight (BMI>25 kg/m²), including $4(3.8 \%)$ with obesity (BMI>30 kg/m²).

The next stage of our research was aimed at analysing the quantitative characteristics of cardiovascular risk factors in patients with impaired EIVD (Table 4). The data proved that the level of atherogenic lipids (LDL and HDL) was the sole indicator of significant differences between patients with normal and impaired EIVD. On the other hand, it was found that patients in groups with normal and low EDVD were comparable regarding most cardiovascular risk factors. Thus, traditional factors are unlikely to play a major role in the processes of endothelial wall remodullation and EDVD occurrence.

Further cardiovascular risk for the examined patients was established, the value for the study group (3.4 \% [1.8; 5.4]) being about in three times higher than the risk value for the general population. It should be noted that the average cardiovascular risk in the patients with impaired EDVD was $2.8 \%$ as compared to the index in normal EIVD - 3.9\%.

\section{Discussion}

Brachial artery active response to exogenous nitrate in patients with AS proves more comparable index of reactivity of brachial artery, that is indicative of the ratio between EIVD and EDVD. A recent research suggests that excessive response of brachial artery to exogenous nitrate in patients with AS is associated with deficient endogenous production of nitric oxide and can be regarded as a sign of endothelial dysfunction $[5,6]$. The obtained findings prove

Table 4. Summary of cardiovascular risk factors and hypertension in patients with normal and reduced endothelium vasodilation

\begin{tabular}{|c|c|c|c|c|c|}
\hline Markers & \multicolumn{2}{|c|}{ EDVD $>10 \%(n=31)$} & \multicolumn{2}{|c|}{ EDVD $<10 \%(n=26)$} & $p$ \\
\hline Average age, years & \multicolumn{2}{|c|}{$36.8 \pm 8.2$} & \multicolumn{2}{|c|}{$38.8 \pm 8.8$} & $p>0.05$ \\
\hline BMI, $\mathrm{kg} / \mathrm{m}$ & \multicolumn{2}{|c|}{$22.8 \pm 4.3$} & \multicolumn{2}{|c|}{$23.9 \pm 4.1$} & $p>0.05$ \\
\hline \multirow[t]{2}{*}{ Smoking } & $\mathrm{n}$ & $\%$ & $\mathrm{n}$ & $\%$ & \\
\hline & 12 & 39 & 10 & 38 & $p>0.05$ \\
\hline History of smoking, years & \multicolumn{2}{|c|}{$10.2 \pm 2.4$} & \multicolumn{2}{|c|}{$9.2 \pm 1.9$} & $p>0.05$ \\
\hline \multirow[t]{2}{*}{ Family history of early heart disease } & $\mathrm{n}$ & $\%$ & $\mathrm{n}$ & $\%$ & \\
\hline & 6 & 19 & 4 & 15 & $p>0.05$ \\
\hline $\mathrm{TCh}, \mathrm{mmol} / \mathrm{l}$ & \multicolumn{2}{|c|}{$4.52 \pm 0.94$} & \multicolumn{2}{|c|}{$4.28 \pm 0.81$} & $p>0.05$ \\
\hline $\mathrm{HDL}, \mathrm{mmol} / \mathrm{l}$ & \multicolumn{2}{|c|}{$1.16 \pm 0.31$} & \multicolumn{2}{|c|}{$0.71 \pm 0.21$} & $\mathrm{p}<0.05$ \\
\hline LDL, mmol/l & \multicolumn{2}{|c|}{$2.61 \pm 0.18$} & \multicolumn{2}{|c|}{$3.22 \pm 0.29$} & $\mathrm{p}<0.05$ \\
\hline Tg, $\mathrm{mmol} / \mathrm{l}$ & \multicolumn{2}{|c|}{$1.15 \pm 0.44$} & \multicolumn{2}{|c|}{$1.32 \pm 0.58$} & $p>0.05$ \\
\hline Atherogenic index & \multicolumn{2}{|c|}{$3.4 \pm 1.21$} & \multicolumn{2}{|c|}{$3.9 \pm 1.26$} & $p>0.05$ \\
\hline TIM of common carotid artery, mm & \multicolumn{2}{|c|}{$0.89 \pm 0.12$} & \multicolumn{2}{|c|}{$1.32 \pm 0.18$} & $\mathrm{p}<0.05$ \\
\hline \multirow[t]{2}{*}{ Arterial hypertension } & $\mathrm{n}$ & $\%$ & $\mathrm{n}$ & $\%$ & \\
\hline & 7 & 22.5 & 6 & 23.1 & $\mathrm{p}>0.05$ \\
\hline Systolic arterial pressure, mm.hg. & \multicolumn{2}{|c|}{$124.5 \pm 18.3$} & \multicolumn{2}{|c|}{$122.5 \pm 22.5$} & $p>0.05$ \\
\hline Diastolic arterial pressure, mm.hg. & \multicolumn{2}{|c|}{$78.5 \pm 14.5$} & \multicolumn{2}{|c|}{$76.5 \pm 18.5$} & $p>0.05$ \\
\hline
\end{tabular}

Note: $p$ - significant differences between $E D<10 \%$ and $E D>10 \%$. 
that output diameter and wall thickness of brachial artery in the patients with AS were significantly higher than similar indices in the control group, and the rate of blood flow through the artery was virtually identical. This may evidence the signs of brachial artery remodelling in patients with AS, endothelium is crucial $[5,6]$.

The detected changes of lipid profile are typical for the patients with systemic inflammatory diseases, and are consistent with the literature [11].

It should be emphasized that a high cardiovascular risk in patients with AS cannot be explained from the standpoint of the analysis of classical risk factors, as they do not explain high incidence of patients with endothelium dependent vasodilatation, which is a significant predictor of cardiovascular problems in patients with inflammatory diseases of joints.

\section{References}

1. Braun J, Sieper J. Ankylosing spondylitis. Lancet. 2007;369:1379-1390.

2. Braun J, van den Berg R, Baraliakos $X$, et al. 2010 update of the ASAS/EULAR recommendations for the management of ankylosing spondylitis. Ann Rheum Dis. 2011;70(6):896-904.

3. Brown MA, Kenna T, Wordsworth BP (2016) Genetics of ankylosing spondylitis-insights into pathogenesis. Nat Rev Rheumatol.12:81-91.

4. Chen HA, Chen $\mathrm{CH}$, Liao HT, et al. Clinical, functional, and radiographic differences among juvenileonset, adult-onset, and late-onset ankylosing spondylitis. J Rheumatol. 2012;39(5):1013-8.

5. Erre GL, Sanna P, Zinellu A, Ponchietti A, Fenu P, Sotgia S, Carru C, et al. Plasma asymmetric dimethylarginine (ADMA) levels and atherosclerotic disease in ankylosing spondylitis: a cross-sectional study. Clin Rheumatol. 2001;30:21-27.

6 . Heeneman S. Cardiovascular risks in spondyloarthritides. Curr Opin Rheumatol. 2007. 19:358362.

7. Kumar A, Falodia SK, Shankar S, Grover R, Marwaha V, Aneja R, Srivastava K, Das N. Assessment of serum nitrite as biomarker of disease activity in

\section{Conclusions}

Our findings suggest high prevalence of ED in patients with AS ( $47 \%$ cases). ED $<10 \%$ caused significant increase in the number of patients with $\mathrm{LDL}>1.7 \mathrm{mmol} / \mathrm{dL}, \mathrm{HDL}-\mathrm{C}<1.0 \mathrm{mmol} / \mathrm{L}$, TIM thickening $>0.9 \mathrm{~mm}$. At the same time, in this group of patients a significantly longer duration of disease and substantial differences in the course in VAS, CRP and ESR indices, as well as activity index and functional disorders were revealed. With the QRisk score scale, SS risk was established as $3.4 \%$ that is about three times higher than the risk among the general population. Among the traditional factors, increased HDL and decreased LDL are most often reported. Thus, the problem of CVD is one of the most important aftermaths of systemic inflammatory disease that is associated with the development of endothelial dysfunction and increased levels of atherogenic lipids.

ankylosing spondylitis. Indian J Rheumatology. 2009;4:47-50.

8. McCarey D, Sturrock RD. Comparison of cardiovascular risk in ankylosing spondylitis and rheumatoid arthritis. Clin Exp Rheumatol. 2009;27:S124S126.

9. Celermajer DS, Sorensen KE, Gooch VM, et al. Non-invasive detection of endothelial dysfunction in children and adults at risk of atherosclerosis. Lancet. 1992;340:1111-1115.

10. Poddubnyi DA, Rebrov AP. Endothelial dysfunction in patients with Bechterew's disease (ankylosing spondylitis). Klin Med (Mosk). 2007;85:66-69.

11. Syngle A, Vohra K, Sharma A, Kaur L. Endothelial dysfunction in ankylosing spondylitis improves after tumor necrosis factor-a blockade. Clin Rheumatol. 2010;29:763-770.

12. Taurog JD, Chhabbra A, Colbert RA. Axial spondyloarthritis and ankylosing spondylitis. New Engl J Med. 2016;26:2563-2574.

13. Unified clinical protocols of primary, emergency and secondary (specialized) medical help: Arterial hypertension. http://www.moz.gov.ua/ua/ portal/allresources/. Accessed 2016. 